\title{
Ductile Fracture Behavior of Bainite-MA Dual Phase Steels
}

\author{
Junji SHIMAMURA, ${ }^{1) *}$ Shusaku OTA, ${ }^{2)}$ Kyono YASUDA $^{2)}$ and Nobuyuki ISHIKAWA ${ }^{1)}$ \\ 1) Steel Research Laboratory, JFE Steel Corporation, 1-1 Minamiwatarida-cho, Kawasaki, Kanagawa, $210-0855$ Japan. \\ 2) Steel Research Laboratory, JFE Steel Corporation, 1 Kokan-cho, Fukuyama, Hiroshima, 721-8501 Japan.
}

\author{
(Received on May 27, 2016; accepted on August 17, 2016)
}

\begin{abstract}
In order to clarify ductile fracture behavior such as void nucleation, crack initiation and crack propagation in bainite-MA dual phase steels, instrumented Charpy impact tests and static bending tests with Charpy specimens were conducted (here, "bainite" has the same meaning as bainitic ferrite). In bainite-MA steels with smaller MA volume fractions and finer MA sizes, the sample showed higher Charpy absorbed energy with higher crack initiation energy and crack propagation energy. From SEM observation of the instrumented Charpy fracture specimens, it was found that void nucleation was enhanced around the boundaries between bainitic ferrite and coarser MA. Based on the results of the static bending tests with Charpy specimens, bainite-MA steels with smaller MA volume fractions and finer MA sizes showed higher void nucleation strain and crack initiation strain. From a finite element analysis of local plastic strain around the boundaries between bainitic ferrite and MA, it was concluded that the equivalent plastic strain decreases in the case of finer MA and longer distance between two MAs compared to coarser MA and shorter distance between two MAs.
\end{abstract}

KEY WORDS: MA; bainite; void nucleation; crack initiation; instrumented Charpy impact test; static bending test; stress triaxiality; equivalent plastic strain; finite element analysis.

\section{Introduction}

In order to secure the safety and reliability of pipelines in earthquake or seismic regions, it is quite important to apply high deformable linepipe steels with sufficient strain capacity against buckling and weld fracture caused by large ground movement. Using steels with a lower $\mathrm{Y} / \mathrm{T}$ (yieldto-tensile strength) ratio, higher strain hardenability and higher uniform elongation is effective for improving the strain capacity of linepipes and preventing buckling or weld fracture. ${ }^{1,2)}$

High deformable linepipe steels are obtained by control of dual phase microstructures such as ferrite-bainite and bainite-MA (here, "bainite" has the same meaning as bainitic ferrite $\left(\alpha_{\mathrm{B}}\right)$ and MA means martensite-austenite constituent). ${ }^{3,4)}$ Tensile properties can be controlled by adjusting the volume fraction of the second phase and the strength difference between the soft and hard phases. ${ }^{5-7)}$ The bainite-MA microstructure is obtained by the heat treatment on-line process (HOP). Resistance to strain aging has been improved by reducing the dislocation density and solute carbon in the bainitic ferrite phase. ${ }^{2)}$ On the other hand, dual phase steels tended to show lower absorbed energy in the upper shelf region of the Charpy impact test compared to steels with a single phase microstructure. ${ }^{8)}$

Several studies have examined ductile fracture behavior related to void nucleation, growth and coalescence in tensile tests $^{5-7,9)}$ and Charpy impact tests. ${ }^{10-12)}$ In dual phase steels,

\footnotetext{
* Corresponding author: E-mail: j-shimamura@jfe-steel.co.jp DOI: http://dx.doi.org/10.2355/isijinternational.ISIJINT-2016-326
}

strain concentrations occur at the boundary between the soft and hard phases. ${ }^{5,9)}$ This seems to enhance void nucleation and growth at those boundaries, resulting in crack propagation in tensile tests. In studies by Ohata et al., equivalent plastic strain around the notch tip and stress triaxiality are described as key factors in ductile crack initiation and propagation. ${ }^{13,14)}$ The effects of initial inclusions and second phases such as pearlite on void nucleation, growth and coalescence were also studied, ${ }^{6,7,15-17)}$ and computational analysis was conducted using a damage parameter based on the Gurson, Tvergaard and Needleman (GTN) model. ${ }^{6,7,18,19)}$ It was found that the volume fraction of initial inclusions and pearlite strongly affected void nucleation strain and the critical void volume fraction when a crack initiated.

In addition, in bainite-MA dual phase steels, the Charpy energy in the upper shelf region was strongly affected by the MA volume fraction. The samples with smaller MA volume fractions showed higher Charpy energy. ${ }^{10)}$ However, in bainite-MA dual phase steels, the effect of microscopic aspects such as the MA volume fraction and its size and dispersion state on crack initiation behavior related to void nucleation, growth and coalescence has not been clarified sufficiently. Therefore, in this study, the ductile fracture behavior of bainite-MA dual phase steels was investigated through instrumented Charpy impact tests and static bending tests with Charpy specimens experimentally and analytically. A finite element analysis was also conducted to investigate the effect of microscopic aspects such as the MA volume fraction, size and dispersion state on local plastic strain concentration around the boundary between MA and bainitic ferrite. 


\section{Experimental Procedure}

\subsection{Sample Preparation}

Samples of $0.05 \mathrm{C}-0.15 \mathrm{Si}-1.8 \mathrm{Mn}-0.02 \mathrm{Nb}$ (Table 1) were melted in an actual steelmaking plant and then cast into ingots of about 200 tons. Ingots with the thickness of 220 $\mathrm{mm}$ were reheated at $1150^{\circ} \mathrm{C}$ for solution treatment and subsequently hot-rolled to make two plate samples with the thickness of $22 \mathrm{~mm}$. Controlled rolling was carried out in the austenite single phase region and below the recrystallizing temperature. After hot rolling, accelerated cooling (AC) was applied from above the Ar3 temperature. Subsequent heat treatments after $\mathrm{AC}$ were then performed to manufacture bainite-MA dual phase steels. This process simulates the online heat treatment process, as the sample is cooled to an intermediate temperature by $\mathrm{AC}$ and then heated immediately to below Ac1. ${ }^{20)}$ Plate Samples A and B were subjected to accelerated cooling to below $550^{\circ} \mathrm{C}$ and subsequently heated to above $650^{\circ} \mathrm{C}$ by using a high frequency heating furnace. Samples $\mathrm{C}$ and D were subjected to accelerated cooling to below $520^{\circ} \mathrm{C}$ and then heated to above $650^{\circ} \mathrm{C}$ by the high frequency heating furnace. After the final heat treatment, the samples were air-cooled. All temperature measurements were carried out by using a radiation thermometer for the plate surface. With Samples A and $\mathrm{C}$, the specimens for mechanical tests and microstructure observations were obtained from the quarter thickness location (1/4 t) of the rolled plate, and with Samples B and $\mathrm{D}$, those specimens were obtained from the middle thickness location $(1 / 2 \mathrm{t})$ of the rolled plate. Four bainite-MA dual phase steels with different MA volume fractions, MA sizes and bainitic ferrite sizes were prepared in this manner.

\subsection{Mechanical Properties}

Tensile and Charpy impact test specimens were obtained from the quarter thickness location (1/4 t, Samples A and C) and the middle thickness location (1/2 t, Samples B and D) of the rolled plates, as described above. Round bar tensile test specimens having the gage diameter of $6.0 \mathrm{~mm}$ and gage length of $25 \mathrm{~mm}$ were taken from the transverse direction (TD) to the rolling direction. Tensile tests were carried out at room temperature with a crosshead speed of $2.0 \mathrm{~mm} / \mathrm{min}$. Instrumented Charpy impact tests were performed on standard Charpy $2 \mathrm{~mm} \mathrm{V-notch} \mathrm{specimens} 10 \mathrm{~mm}$ square and $55 \mathrm{~mm}$ in length, oriented in the TD direction. The test temperatures were $-115,-80,-50$ and $-20^{\circ} \mathrm{C}$. In the $-20^{\circ} \mathrm{C}$ tests, total absorbed energy (vEt) was evaluated, after which crack initiation energy (vEi) and crack propagation energy (vEp) were evaluated. ${ }^{21)}$ Here, vEi and vEp were defined as energy before and after maximum load, respectively.

\subsection{Ductile Fracture Behavior through Void Nucle- ation, Growth and Coalescence}

In order to clarify the effect of MA morphology on ductile fracture behavior through void nucleation, growth and coalescence, static bending tests with Charpy specimens were conducted at several displacement levels with Samples A and B. Figure 1 shows the test procedure. The punch stroke was stopped in each displacement from $0.1 \mathrm{~mm}$ to $8.0 \mathrm{~mm}$, and the macrostructure in the center of thickness position around the notch tip of the Charpy specimen was
Table 1. Chemical composition of steel plate samples.

\begin{tabular}{cccccccc}
\hline $\mathrm{C}$ & $\mathrm{Si}$ & $\mathrm{Mn}$ & $\mathrm{P}$ & $\mathrm{S}$ & $\mathrm{Nb}$ & Others & Ceq (\%) \\
\hline 0.05 & 0.16 & 1.80 & 0.008 & 0.0005 & 0.02 & $\mathrm{Ni}, \mathrm{Mo}$, etc. & 0.44 \\
\hline
\end{tabular}

$\mathrm{Ceq}=\mathrm{C}+\mathrm{Mn} / 6+\mathrm{Cu} / 15+\mathrm{Ni} / 15+\mathrm{Cr} / 5+\mathrm{Mo} / 5+\mathrm{V} / 5$

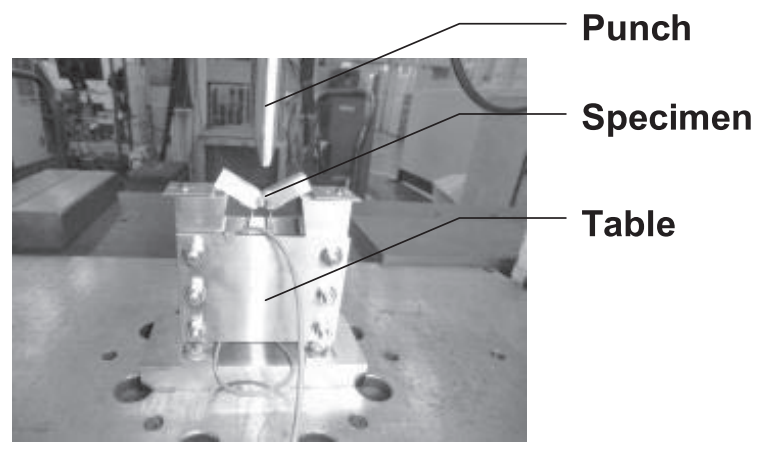

Fig. 1. Procedure of static bending test with Charpy specimen.

observed by optical microscopy.

In order to investigate the equivalent plastic strain at void nucleation and ductile fracture initiation, a finite element analysis (FEA) was also conducted, as described in section 4.2 .

\subsection{Microstructure Observation and Nano Hardness Evaluation of Each Phase}

Microstructure observations of the four bainite-MA dual phase steels were carried out by using a conventional scanning electron microscope (SEM) and a field emission scanning electron microscope (FE-SEM). The details of the microstructures of the steels were investigated by using an FE-SEM equipped with electron backscatter diffraction (EBSD). To distinguish second phases such as cementite and MA, SEM observation was carried out by the two stage etching method. ${ }^{20)}$ The MA volume fraction and its size were measured by using SEM photos with magnification of 2000x. The MA size is defined by the average diameter equivalent to a circle from the SEM photos. The bainitic ferrite size is defined by the average diameter equivalent to a circle from the average grain area surrounding the boundaries with $15^{\circ}$ or more, which was obtained from the EBSD IPF map. To investigate the void nucleation behavior, the microstructure in the center of thickness position around the notch tip of the Charpy specimen was also observed.

Nano hardness evaluations of each phase in each sample were conducted by using a nano indentation machine. The test load was $1000 \mu \mathrm{N}$.

\section{Results}

\subsection{Microstructures of Four Bainite-MA Dual Phase Steels}

Figure 2 shows the SEM photos of each sample. Many MA were seen in the bright white areas shown in photos. In each sample, MA had an island shape or a lath-like shape and was dispersed randomly within the slightly deformed bainitic ferrite matrix. Table 2 shows the characteristics of 
bainite-MA microstructure of each sample. Figure 3 shows the distribution of the MA size in each sample. Sample B had the largest MA volume fraction and also had the largest MA size compared to the other samples. Sample C had the smallest MA volume fraction and MA number fraction.

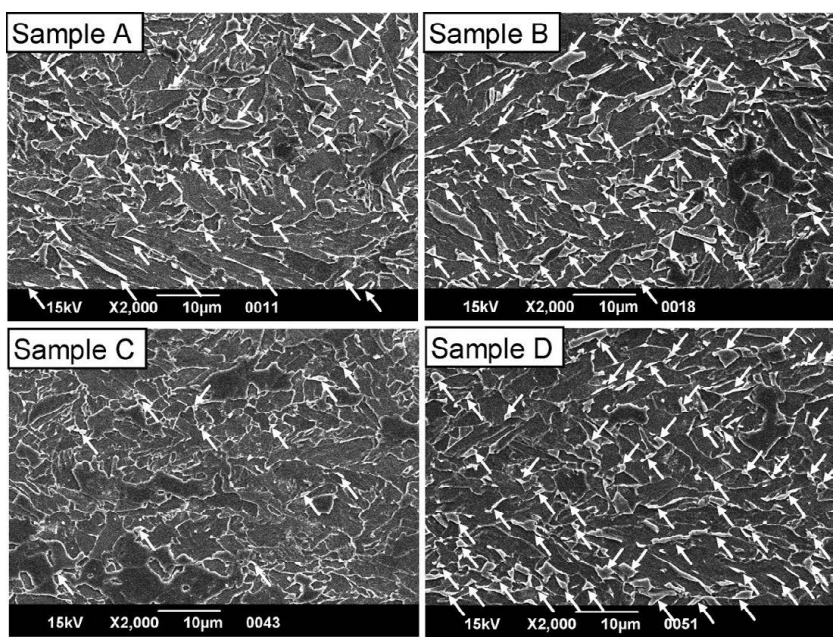

Fig. 2. Typical SEM photos of each sample. MA is recognized as the areas of bright contrast shown by arrows.

Table 2. Characteristics of bainite-MA microstructure of each sample.

\begin{tabular}{cccccccc}
\hline & $\begin{array}{c}\text { MA } \\
\text { Sample } \\
\text { No. }\end{array}$ & $\begin{array}{c}\text { volume } \\
\text { fraction } \\
(\%)\end{array}$ & $\begin{array}{c}\text { MA } \\
\text { size } \\
(\mu \mathrm{m})\end{array}$ & $\begin{array}{c}\text { MA } \\
\text { number } \\
\text { fraction } \\
\left(10^{3} / \mathrm{mm}^{2}\right)\end{array}$ & $\begin{array}{c}\alpha_{\mathrm{B}} \text { grain } \\
\text { diameter } \\
(\mu \mathrm{m})\end{array}$ & $\begin{array}{c}\text { Nano } \\
\text { hardness } \\
(\mathrm{GPa})\end{array}$ & $\begin{array}{c}\text { Hardness } \\
\text { ratio }\end{array}$ \\
\hline A & 7.4 & 1.1 & 74 & 4.3 & 3.6 & 10.9 & 3.0 \\
B & 13.7 & 1.4 & 80 & 4.9 & 3.2 & 8.9 & 2.8 \\
C & 1.1 & 0.9 & 17 & 4.1 & 3.5 & - & - \\
D & 8.7 & 1.1 & 77 & 5.0 & 3.3 & 9.0 & 2.1 \\
\hline
\end{tabular}

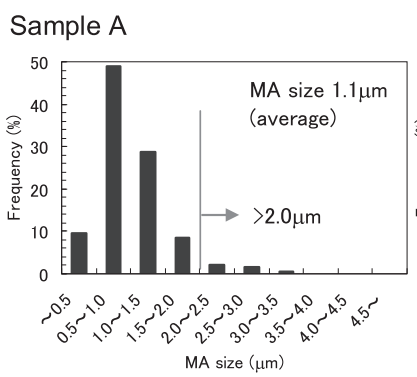

Sample B

Sample C

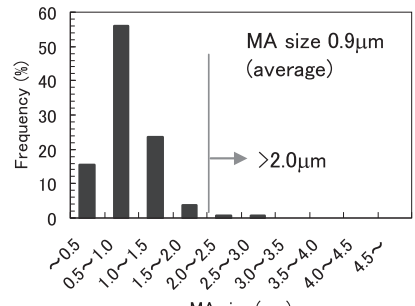

Sample D

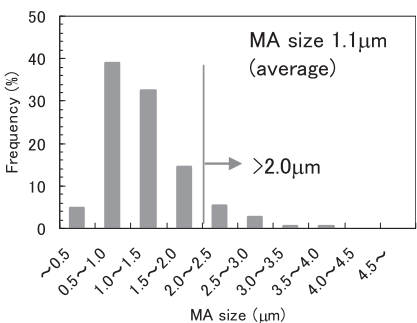

Fig. 3. MA size distribution of each sample.

\subsection{Mechanical Properties}

Table 3 shows the tensile strength (TS) and the $0.5 \%$ yield strength (YS) of the specimens. The values of the YS to TS ratio (YR), uniform elongation (uEl) and total elongation (El) are also shown in Table 3. Figure 4 shows the stress-strain curves of each sample. The base tensile strengths of Samples A and B were on almost the same level. The base tensile strengths of Samples C and D were also approximately the same. Sample B, which had the largest MA volume fraction, had the lowest $\mathrm{Y} / \mathrm{T}$ ratio (YR) and the lowest $\mathrm{uEl}$ and El. The shorter distance between two MAs seemed to affect this deterioration of ductility in the tensile tests of Sample B, as will be discussed in section 4.2.

Figure 5 shows the results of the instrumented Charpy impact tests. Table 4 shows the absorbed energy at $-20^{\circ} \mathrm{C}$ in the instrumented Charpy impact tests. Figure 6 shows the load-displacement curves of the instrumented Charpy impact tests for each sample. It was found that these samples had a fully $100 \%$ shear area at $-20^{\circ} \mathrm{C}$. This means that full ductile fracture occurred in these samples at $-20^{\circ} \mathrm{C}$ in the Charpy impact tests. Sample A had higher vEt at $-20^{\circ} \mathrm{C}$

Table 3. Mechanical properties of each sample (round bar tensile test).

\begin{tabular}{cccccc}
\hline Sample No. & 0.5YS (MPa) & TS (MPa) & YR (\%) & uEl (\%) & El (\%) \\
\hline A & 551 & 709 & 78 & 10.4 & 32.8 \\
B & 512 & 711 & 72 & 7.3 & 24.0 \\
C & 576 & 650 & 89 & 10.7 & 32.0 \\
D & 514 & 655 & 78 & 10.9 & 28.0 \\
\hline
\end{tabular}

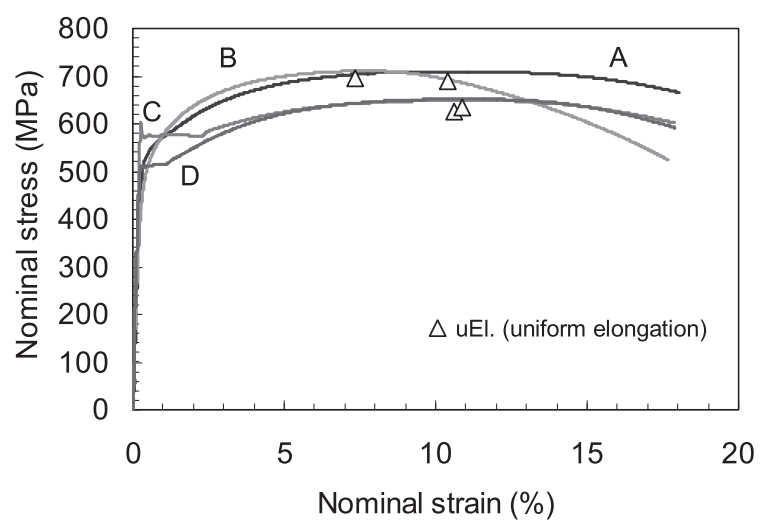

Fig. 4. Nominal stress-strain curves of each sample. a) Absorbed energy

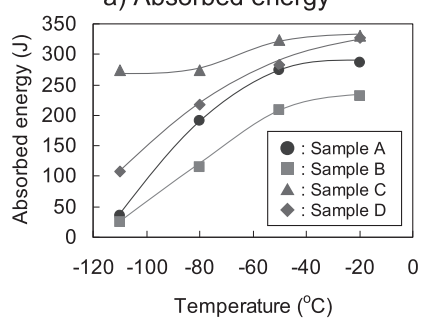

b) Brittle area

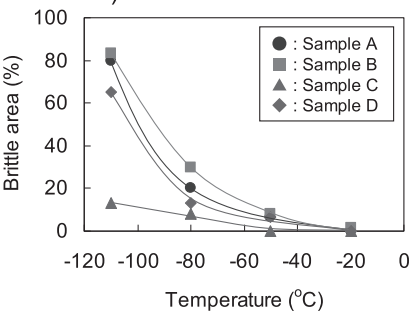

Fig. 5. Results of instrumented Charpy impact tests, a) absorbed energy and b) fraction of brittle area. 
Table 4. Crack initiation energy and crack propagation energy from instrumented Charpy impact tests.

\begin{tabular}{ccccccccc}
\hline \multirow{2}{*}{$\begin{array}{c}\text { Sample } \\
\text { No. }\end{array}$} & \multicolumn{2}{c}{ vEt at $-20^{\circ} \mathrm{C}(\mathrm{J})$} & & \multicolumn{2}{c}{ vEi at $-20^{\circ} \mathrm{C}(\mathrm{J})$} & & \multicolumn{2}{c}{ vEp at $-20^{\circ} \mathrm{C}(\mathrm{J})$} \\
\hline & each & Ave. & & each & Ave. & & each & Ave. \\
\hline A & $265,279,305$ & 283 & $57,57,85$ & 66 & & $213,226,223$ & 221 \\
B & $203,248,241$ & 231 & $57,57,58$ & 58 & & $150,193,188$ & 177 \\
C & $341,333,314$ & 329 & $94,99,94$ & 96 & & $248,236,221$ & 235 \\
D & $322,330,331$ & 328 & $99,97,99$ & 98 & & $223,232,234$ & 230 \\
\hline
\end{tabular}

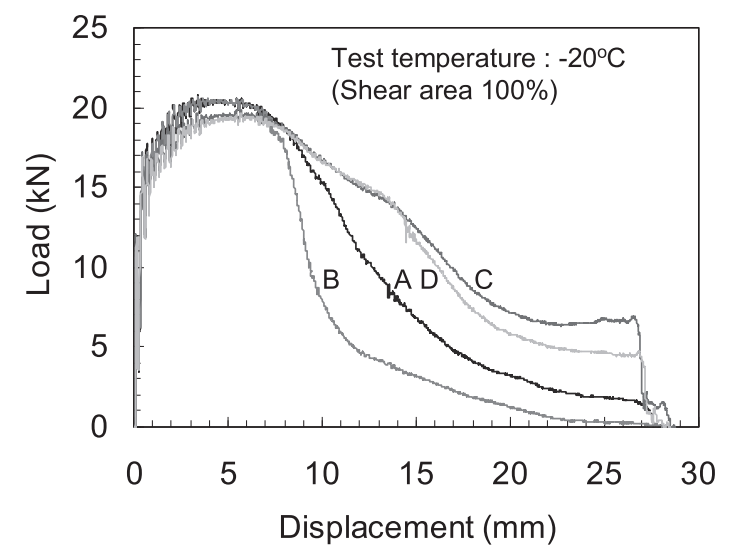

Fig. 6. Load-displacement curves of each sample in instrumented Charpy impact tests.

compared to Sample B. Table 4 also shows the ductile crack initiation energy and the ductile crack propagation energy at $-20^{\circ} \mathrm{C}$ for each sample. Crack initiation energy is defined by the energy before the maximum load point, and crack propagation energy is defined by the energy after the maximum load point. From these results, Sample A had higher initiation and propagation energy compared to Sample B. As Sample B had a high strain hardening ability and showed lower $\mathrm{uEl}$ and $\mathrm{El}$, this sample seems to be prone to heavy damage during ductile fracture through void nucleation, growth and coalescence.

Therefore, in Sample B, the volume fraction of MA and its size seems to affect both the crack initiation energy and the crack propagation energy, and especially the crack propagation energy. Figure 7 shows the relationship between the total absorbed energy (vEt) at $-20^{\circ} \mathrm{C}$ and the MA volume fraction, MA size and bainitic ferrite size. The samples with larger MA volume fractions and larger MA sizes displayed lower absorbed energy at $-20^{\circ} \mathrm{C}$. On the contrary, the effect of the bainitic ferrite size on absorbed energy was not clear. Sample D had higher absorbed energy compared to Sample A, which had almost same levels of MA volume fraction and MA size.

Figure 8 shows the effects of the MA-bainitic ferrite hardness ratio on (a) Charpy absorbed energy at $-20^{\circ} \mathrm{C}$ (vEt) and (b) Y/T ratio. Both vEt and the Y/T ratio tended to decrease as the hardness ratio between MA and bainitic ferrite increased.

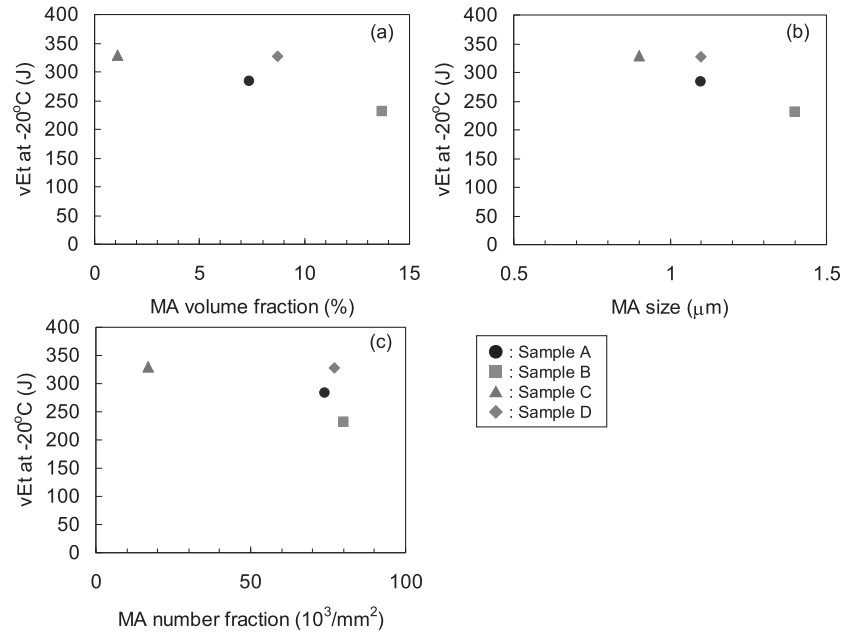

Fig. 7. Relationship between Charpy absorbed energy at $-20^{\circ} \mathrm{C}$ and (a) MA volume fraction, (b) MA size and (c) MA number fraction.
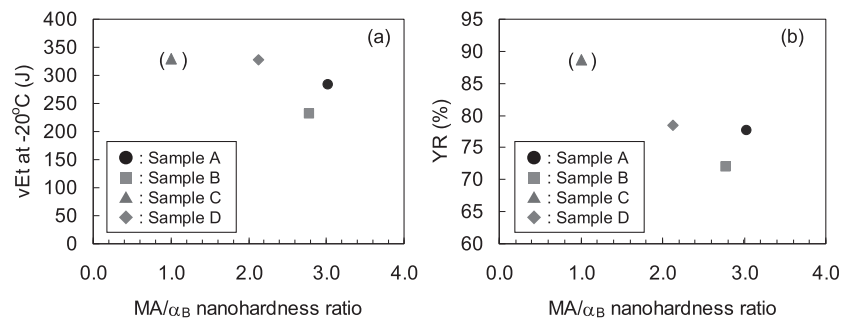

Fig. 8. Effects of MA/bainitic ferrite hardness ratio on (a) Charpy absorbed energy at $-20^{\circ} \mathrm{C}$ and (b) $\mathrm{Y} / \mathrm{T}$ ratio.

\section{Discussion}

\subsection{Void Nucleation, Growth and Coalescence Behavior} 4.1.1. Instrumented Charpy Impact Test

The ductile fracture behavior of bainite-MA dual phase steels is also considered to be strongly affected by void nucleation, growth and coalescence. Therefore, first, the voids in Samples A and B after the Charpy impact tests at $-20^{\circ} \mathrm{C}$ were investigated in order to clarify the effect of the MA volume fraction and size on void formation behavior.

Figure 9 shows SEM photos in the center of thickness position around the notch tip of Samples A and B after the Charpy impact tests at $-20^{\circ} \mathrm{C}$, which is the fully ductile fracture region. Many voids were generated at the boundary between coarser MA and bainitic ferrite in Sample B. On the contrary, in Sample A, many finer voids were generated at the boundary of bainitic ferrites as well as the boundary between MA and bainitic ferrite. A larger number of coarser voids were seen at the boundary between coarser MA and bainitic ferrite in Sample B compared to Sample A. In Sample B, void formation at a lower plastic strain level seems to lead to earlier crack initiation, resulting in lower absorbed energy as described in section 4.1.2 and 4.2.2. In Sample B, it is considered that shorter distance between two MAs lead to higher equivalent plastic strain at the boundary between MA and bainitic ferrite. Thus, in order to suppress void nucleation, growth and coalescence, it seems to be important to reduce the MA volume fraction and to refine 
the MA size.

Sample D showed higher absorbed energy compared to Sample A which had similar MA volume fraction, MA size and MA number fraction in Fig. 8. The lower hardness ratio between MA and bainitic ferrite seems to suppress void nucleation, growth and coalescence, resulting in higher absorbed energy as discussed in section 4.2.2.

\subsubsection{Static Bending Test with Charpy Specimens}

In order to clarify the effect of MA morphology on void nucleation behavior, static bending tests of Charpy specimens were conducted at several displacement levels. In static bending tests, the strain rate and deformation heat are different from those in the dynamic Charpy impact tests. These points must be considered in a future study. Figure 10 shows the macrostructure around the notch tip related to macroscopic crack initiation and propagation. Figure 11 shows the load and notch opening displacement curves of each sample. In these static bending tests, void nucleation and initiation of small cracks with sizes of $20 \mu \mathrm{m}$ or more occurred at an earlier stage before the maximum load. As described by Kobayashi et al., ${ }^{21)}$ the impact speed and microstructure seem to affect these crack initiation behaviors. In Sample B, with the larger MA volume fraction and larger MA size, cracks initiated at an earlier stage of notch opening displacement compared to Sample A.

The microscopic void nucleation, growth and coalescence behavior around the notch tip was also observed by SEM. Figure 12 shows SEM micrographs of the center of thickness position around the notch tips in Samples A and B. The displacements in the static bending tests were $0.5 \mathrm{~mm}$ (equivalent plastic strain: 0.65 ) and $1.0 \mathrm{~mm}$ (equivalent (a) Sample A

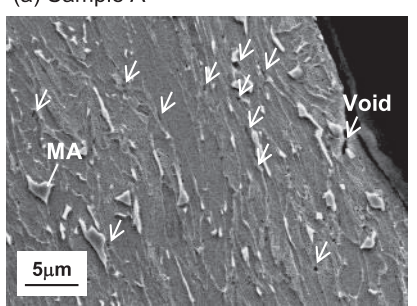

(b) Sample B

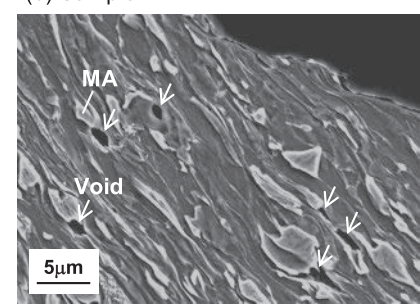

Fig. 9. SEM photos of area around notch tip in (a) Sample A and (b) Sample B (instrumented Charpy impact test at $-20^{\circ} \mathrm{C}$ ).

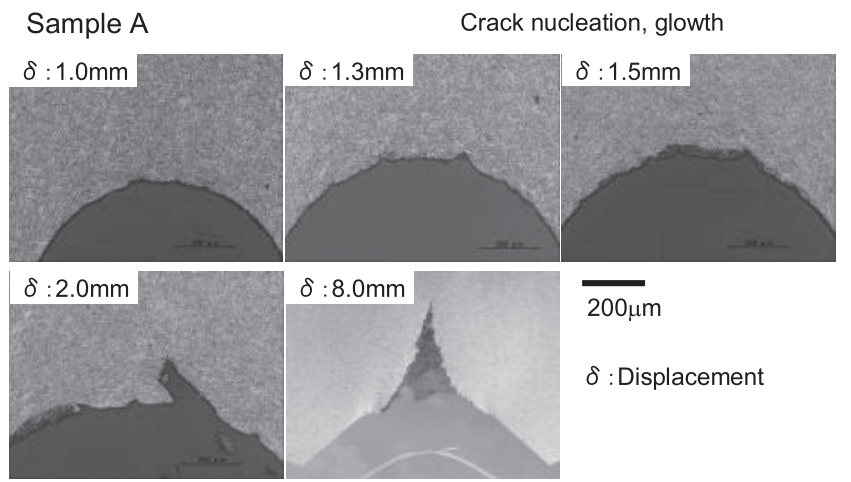

Fig. 10. Crack initiation behavior of Sample A (static bending tests with Charpy specimen, $0.25 \mathrm{R})$. plastic strain: 1.18). These equivalent plastic strains in the center of thickness position around the notch tip were calculated by using a finite element analysis as described in

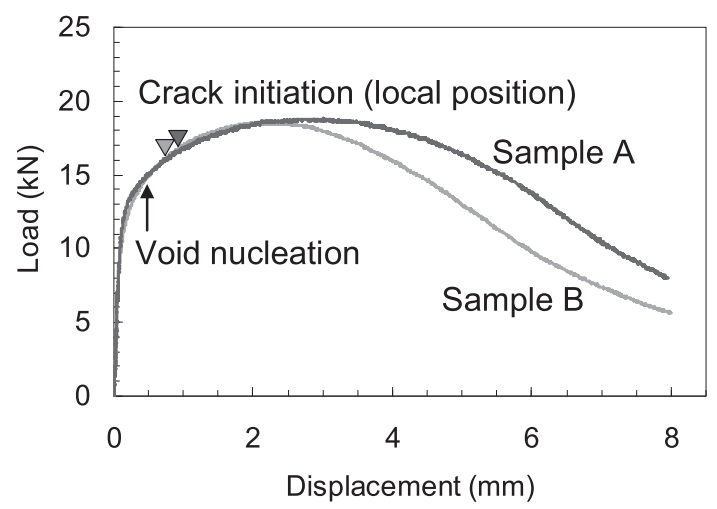

Fig. 11. Load-displacement curves and crack initiation positions of Samples A and B.

\section{Sample A}

$\delta=0.5 \mathrm{~mm}\left(\varepsilon_{\mathrm{q}}=0.65\right.$ at notch tip $)$

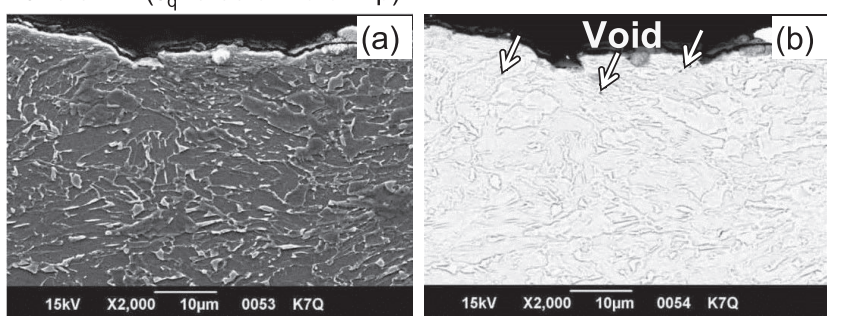

$\delta=1.0 \mathrm{~mm}\left(\varepsilon_{\mathrm{q}}=1.18\right.$ at notch tip $)$

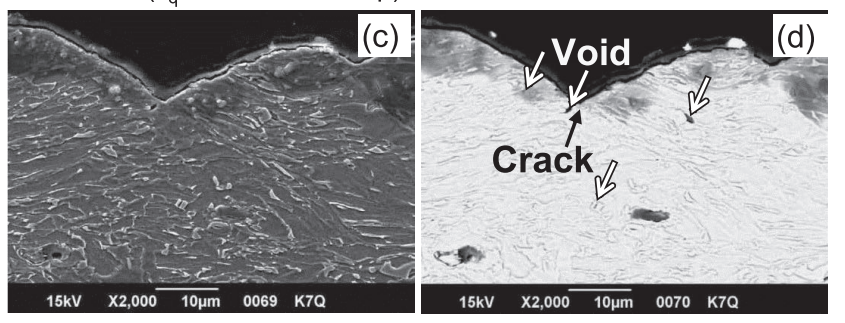

Sample B

$\delta=0.5 \mathrm{~mm}\left(\varepsilon_{\mathrm{q}}=0.65\right.$ at notch tip $)$

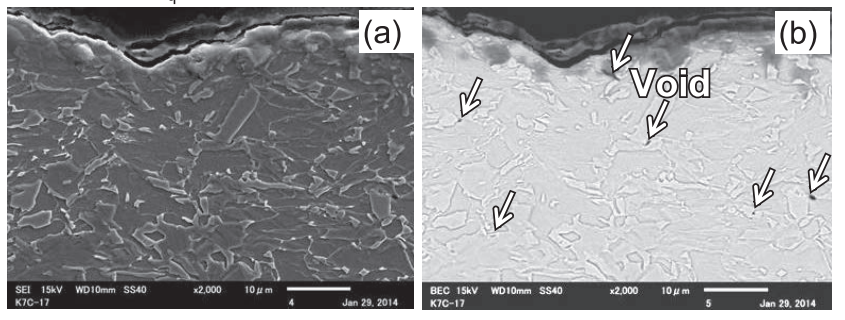

$\delta=1.0 \mathrm{~mm}\left(\varepsilon_{\mathrm{q}}=1.18\right.$ at notch tip $)$

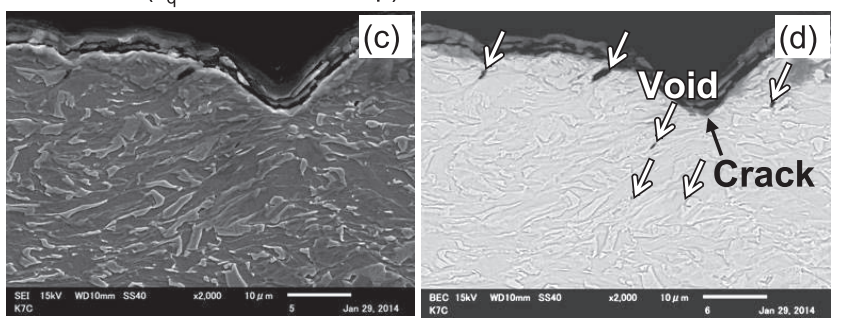

Fig. 12. SEM photos of area around notch tip in Samples A and B (static bending tests with Charpy specimen, $0.25 \mathrm{R}, 0.5-$ $1.0 \mathrm{~mm}$ displacement). 
section 4.2.1. It was found that void nucleation and growth occurred at earlier stages of notch opening displacement of around $0.5 \mathrm{~mm}$ in both Samples A and B. On the other hand, crack initiation occurred at around $1.0 \mathrm{~mm}$ displacement. These results show that voids nucleated at a smaller plastic strain level before crack initiation. Figure 13 shows the relationship between the void area fraction and equivalent plastic strain in the center of thickness position around the notch tip in Samples A and B. These equivalent plastic strains were also calculated as described in section 4.2.1. The void area fractions were measured from four 2000x SEM photos and are plotted here as open marks. The averages of the data for each displacement are plotted as solid marks. Sample B tended to show a higher voids area fraction and a smaller void nucleation strain $\left(\varepsilon_{\mathrm{N}} \sim 0.3\right)$ compared to Sample A $\left(\varepsilon_{\mathrm{N}} \sim 0.4\right)$. In Sample B, void formation at a lower plastic strain level seems to lead to earlier crack initiation, resulting in lower absorbed energy as described in section 4.1.1 and 4.2.2.

\subsection{Finite Element Analysis}

4.2.1. Macroscopic Elasto-plastic Analysis for Static Bending Test with Charpy Specimen

A finite element analysis of the static bending test with

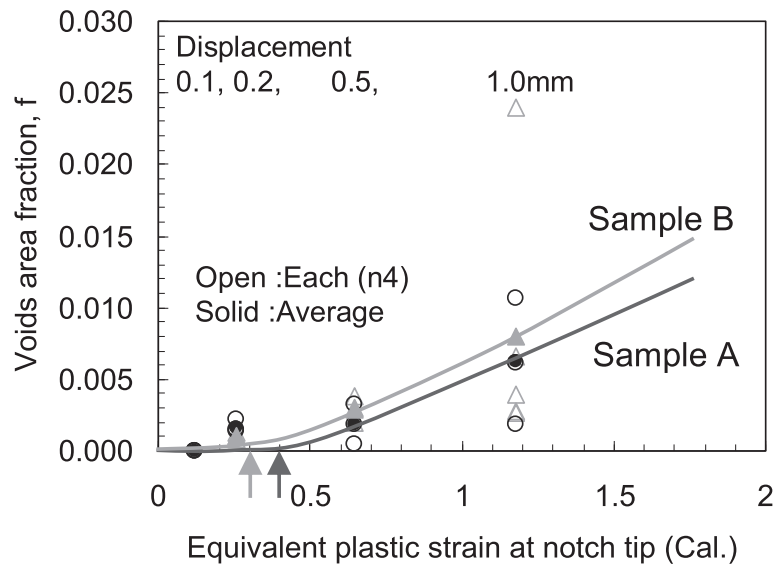

Fig. 13. Void area fraction and equivalent plastic strain at center of thickness position around notch tip in Samples A and B. a Charpy specimen $(0.25 \mathrm{~mm}$ notch root radius $)$ was conducted by using a 3D 1/4 model to investigate the local equivalent plastic strain around the notch tip analytically.

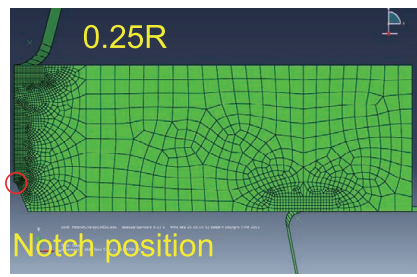

Static bending test with Charpy specimen Solid, 3D, 1/4 model

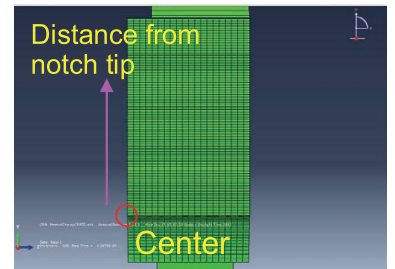

Fig. 14. Finite element model of static bending test with Charpy specimen.

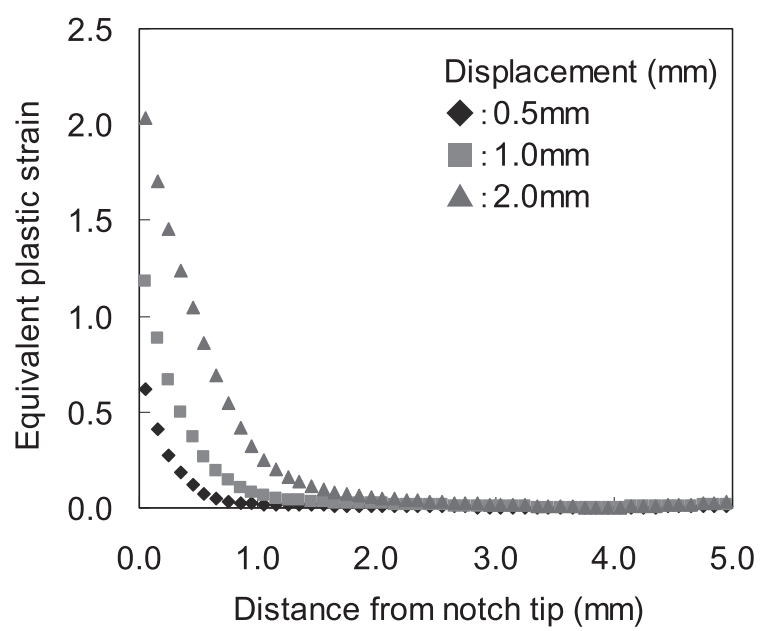

Fig. 15. Equivalent plastic strain at center of thickness position around notch tip during bending deformation.

\section{$0.5 \mathrm{~mm}$ displacement}

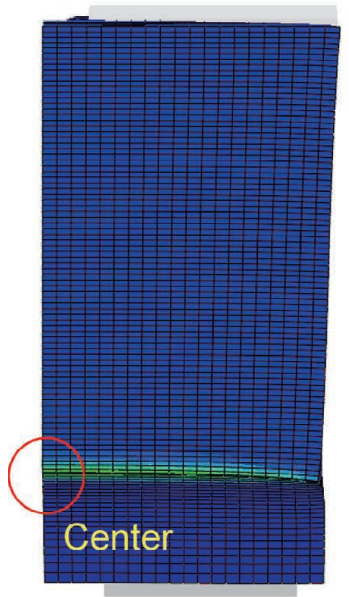

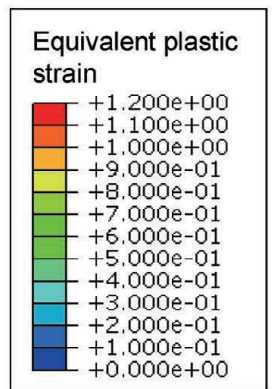

\section{$1.0 \mathrm{~mm}$ displacement}

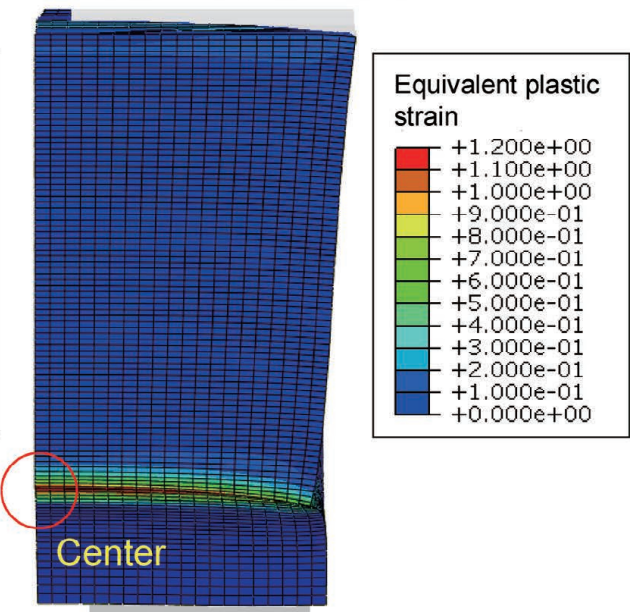

Fig. 16. Contour figure of equivalent plastic strain around notch tip (Sample A, $0.5 \mathrm{~mm}$ and $1.0 \mathrm{~mm}$ displacement). 
ABAQUS Ver. 6.12. was used for this analysis. Figure 14 shows the mesh dimensions of the finite element model of the static bending test with the Charpy specimen. The mesh size of the zone of interest around the notch tip was 0.05 $\mathrm{mm}$. The nominal stress-strain curves of Samples A and B shown in Fig. 4 were used for this calculation.

Stress triaxiality and equivalent plastic strain around the notch tip were evaluated from these calculations. Figure 15 shows the equivalent plastic strain in the center of thickness position around the notch tip in Sample A when the notch opening displacement was $0.5 \mathrm{~mm}, 1.0 \mathrm{~mm}$ and $2.0 \mathrm{~mm}$. The distance from the notch tip was defined as shown in Fig. 14. The equivalent strain immediately below the notch tip increased as the notch opening displacement increased. Figure 16 shows the contour figures around the notch tip when the notch opening displacement was $0.5 \mathrm{~mm}$ and 1.0 $\mathrm{mm}$. Strain concentration occurred at the center of thickness position compared to the strain at the surface position. Figures 17 and 18 show the equivalent plastic strain and the stress triaxiality at the center of thickness position and the surface position around the notch tip, respectively, for Sample A during bending deformation. The equivalent plas-

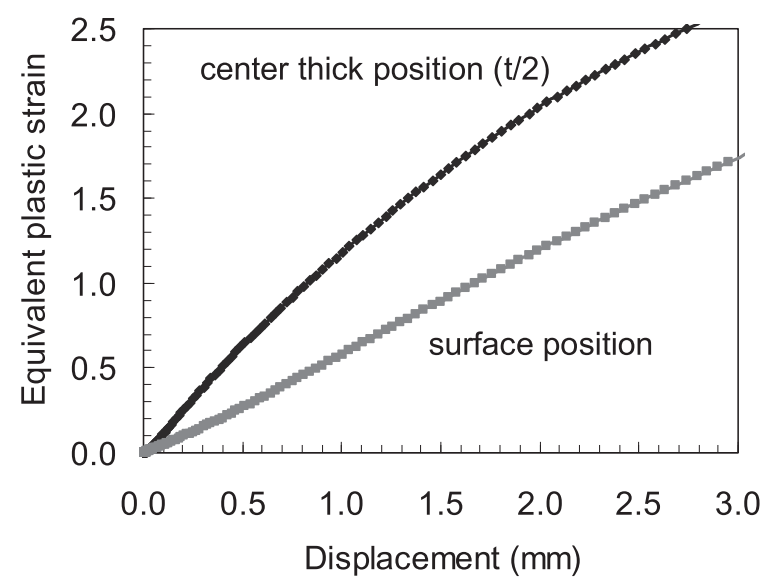

Fig. 17. Equivalent plastic strain at center of thickness and surface positions around notch tip during bending deformation (Sample A).

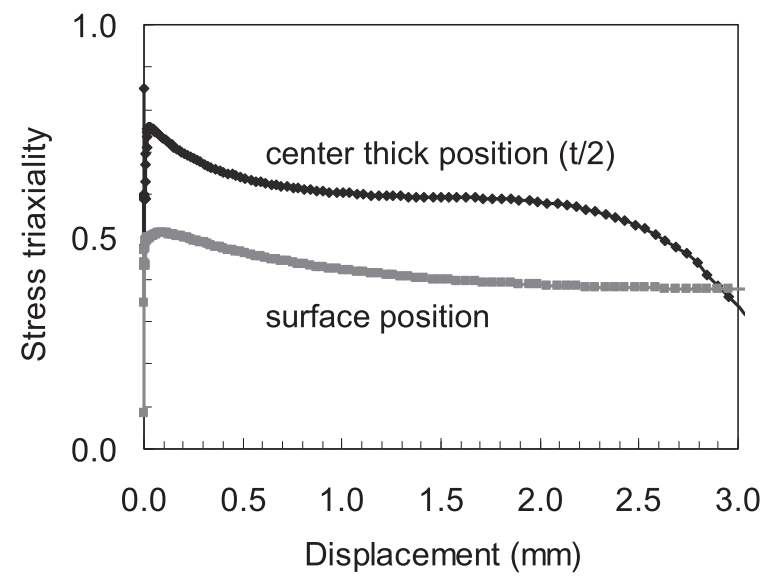

Fig. 18. Stress triaxiality at center of thickness and surface positions around notch tip during bending deformation (Sample A). tic strain and the stress triaxiality at the center of thickness position were higher than those at the surface position. As shown in Fig. 13, the void area fraction increased as the equivalent plastic strain in the center of thickness position increased. From this, it is concluded that the void nucleation behavior of bainite-MA dual phase steels is dependent on the stress triaxiality immediately below the notch tip and the equivalent plastic strain at that position.

\subsubsection{Effect of Bainite-MA Microstructure on Local Plas- tic Strain Concentration}

In order to investigate the effects of microscopic aspects such as the MA volume fraction, size and dispersion state on local plastic strain concentration around the boundary between MA and bainitic ferrite, a finite element analysis was conducted with a 2D model. Figure 19 shows the finite element model of the bainite-MA dual phase steel and the FEA calculation conditions. The MA size, hardness and morphology were changed to investigate their effects on local plastic strain concentration around the boundary between MA and bainitic ferrite. ABAQUS Ver. 6.12 was used for this analysis. The mesh size of the zone of interest around the boundary was $0.05 \mu \mathrm{m}$. The calculation conditions are also shown in Fig. 19. One of the x-axis and y-axis was fixed and uniaxial tensile stress was applied. Figure 20 shows the nominal stress-strain curve used in this calculation. Based on the MA/bainitic ferrite hardness ratio shown in Table 2 and the tensile strength shown in Table 3, a true stress-strain curve for the finite element analysis was prepared by using the Swift equation. The tensile strength of bainitic ferrite and MA were estimated as $600 \mathrm{MPa}$ and $1400 / 1800 \mathrm{MPa}$, respectively.

$$
\sigma=a\left(b+\varepsilon^{p}\right)^{N}
$$

$\sigma$ : true stress, $\varepsilon^{p}$ : true plastic strain, $a, b, N$ : constant values

Figure 21 shows the equivalent plastic strain around the boundary between MA and bainitic ferrite during tensile deformation in Cases $1-3$. These equivalent plastic strains were maximum value in the diagonal $45^{\circ}$ direction. Coarser MA and a shorter distance between two MAs gave higher equivalent plastic strain at the same tensile strain level. Figure 22 is one example at the same tensile strain of 0.10 , comparing Case 1 and Case 3. In Case 3, the equivalent plastic strain around the boundary between MA and bainitic ferrite was higher than that in Case 1, which had finer MA and a longer distance between two MAs. Also in Case 3, the strained region around the boundary between MA and bainitic ferrite becomes much broader than that in Case 1. These calculation results seem to correspond to the experimental results shown in Fig. 9. Sample B in Fig. 9 seems to correspond to Case 3. Coarser MA and a shorter distance between two MAs gives higher equivalent plastic strain around the boundary between MA and bainitic ferrite, and also gives broader strained region from calculation. Therefore, in Sample B, many voids were formed around the boundary between MA and bainitic ferrite, and those voids become broader compared to Sample A. Obtaining finer MA dispersed with a longer distance between two MAs is important for securing higher strain resistance and higher void nucleation strain. Figure $\mathbf{2 3}$ shows the effect of the $\mathrm{MA} /$ bainitic ferrite hardness ratio on the equivalent plastic 


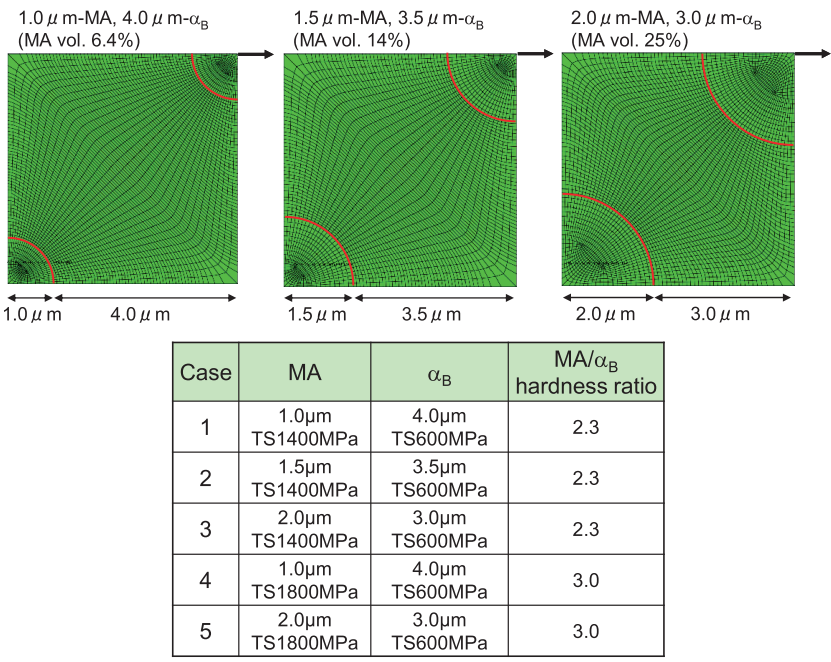

Fig. 19. Finite element model of bainite-MA dual phase steel and calculation conditions.
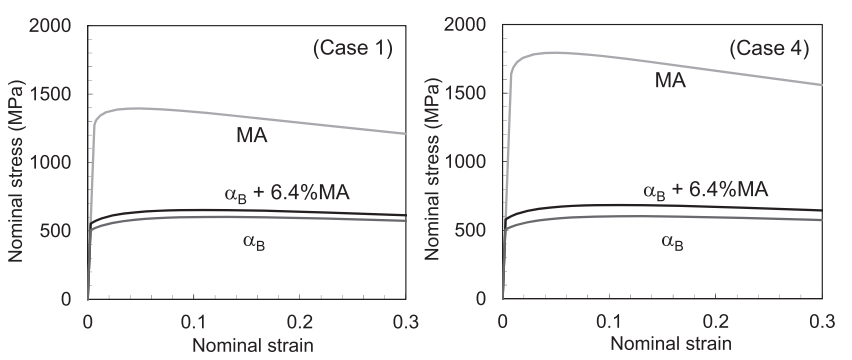

Fig. 20. Nominal stress strain curves used in calculations.

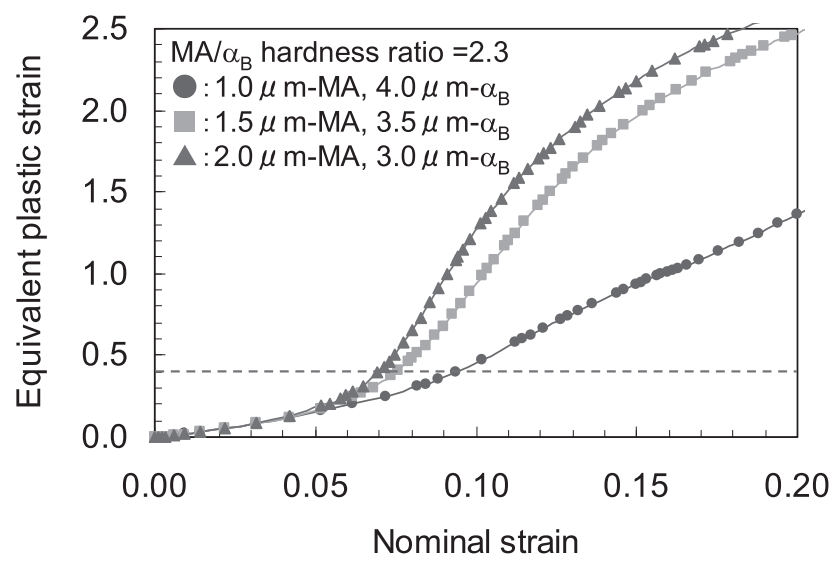

Fig. 21. Equivalent plastic strain around boundary between MA and bainitic ferrite during tensile deformation (Cases $1-3, \mathrm{MA} /$ bainitic ferrite hardness ratio $=2.3$ ).

strain distribution around the boundary between MA and bainitic ferrite. A higher MA/bainitic ferrite hardness ratio gave higher equivalent plastic strain and a broader strained region when the void nucleation strain was assumed to be 0.4 from Sample A in Fig. 13. Sample A corresponds to Case 1 and Sample D corresponds to Case 4. In Case 4, the strained region at 0.40 equivalent strain become about $20 \%$ broader compared to Case 1 . As a result, suppressing the MA/bainitic ferrite hardness ratio is also effective for securing higher strain resistance.

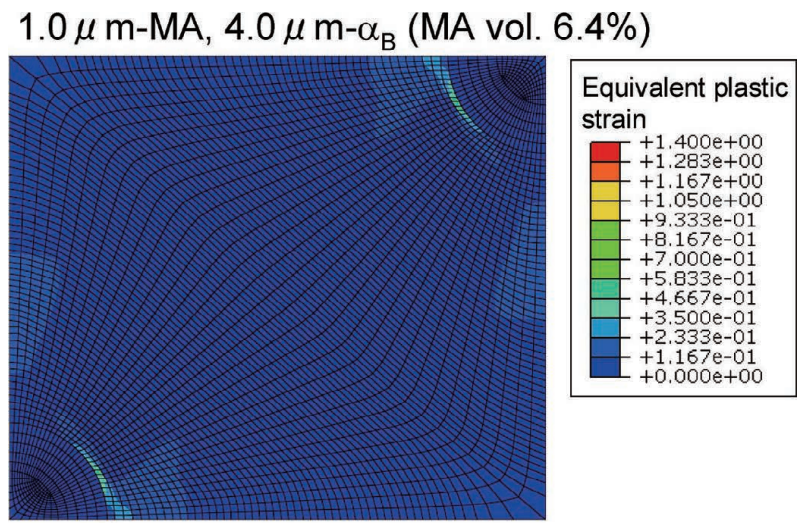

$2.0 \mu \mathrm{m}-\mathrm{MA}, 3.0 \mu \mathrm{m}-\alpha_{\mathrm{B}}$ (MA vol. $25 \%$ )

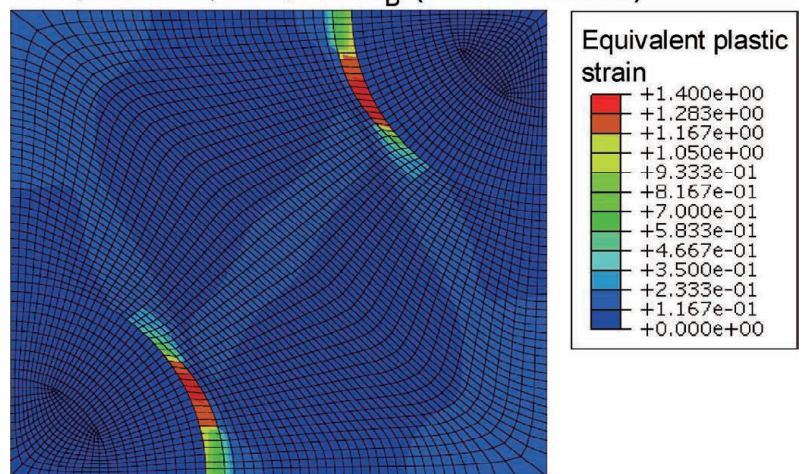

Fig. 22. Contour figures of equivalent plastic strain around boundary between MA and bainitic ferrite (Cases 1 and 3 , nominal strain $=0.10$ ).

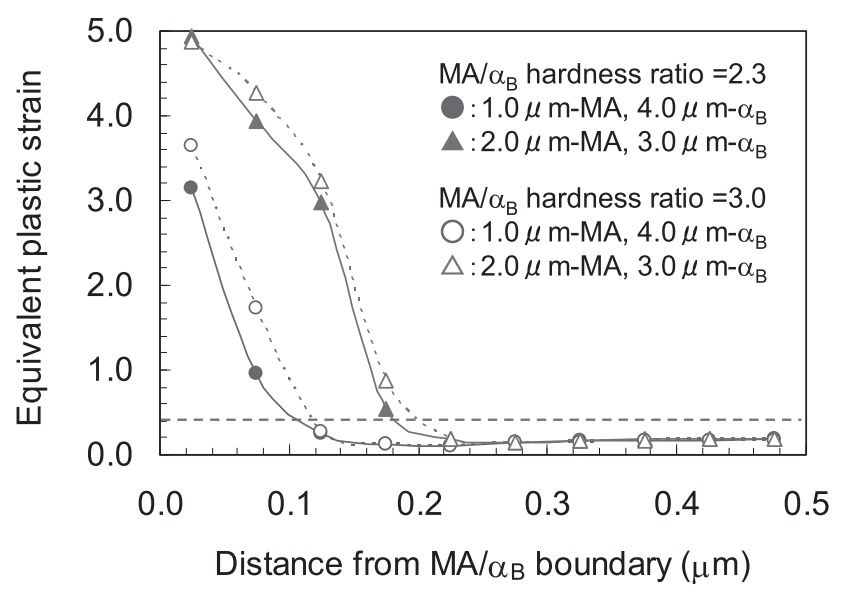

Fig. 23. Equivalent plastic strain distributions around boundary between MA and bainitic ferrite (Cases 1, 3-5, nominal strain $=1.0$ )

\section{Conclusion}

In order to clarify the ductile fracture behavior of bainiteMA dual phase steels in Charpy impact tests, instrumented Charpy impact tests were conducted with four bainite-MA dual phase steel samples having different MA volume fractions and MA sizes. Void formation behavior was investigated after the Charpy impact tests, and static bending tests with Charpy specimens were conducted to investigate void nucleation and crack initiation behavior. A finite element analysis of the static bending test with the Charpy speci- 
men was conducted to clarify the void nucleation strain at the center of thickness position. A finite element analysis was also conducted to investigate the effect of the bainiteMA microstructure on the local plastic strain concentration around the boundary between MA and $\alpha_{\mathrm{B}}$. The main results were summarized as follows.

(1) Sample A with a smaller MA volume fraction and finer MA size showed higher Charpy absorbed energy compared to Sample B, which had larger MA volume fraction and coarser MA size. The Charpy absorbed energy at $-20^{\circ} \mathrm{C}$ of the bainite-MA dual phase steels was strongly affected by the MA volume fraction and its size.

(2) A higher MA volume fraction and coarser MA size enhanced void nucleation around the boundaries between MA and bainitic ferrite, resulting in a larger void area fraction and lower absorbed energy.

(3) In order to clarify the ductile fracture behavior through void nucleation, growth and coalescence and crack initiation around the notch tip, static bending tests with Charpy specimens were conducted. As a result, Sample B with a larger MA volume fraction and coarser MA size showed smaller void nucleation strain and crack initiation strain compared to Sample A with a smaller MA volume fraction and finer MA size.

(4) From the finite element analysis of the static bending test with Charpy specimens, the equivalent strain immediately below the notch tip increased as the notch opening displacement increased. The equivalent plastic strain at the center of thickness position was higher than that at the surface position. As shown in Fig. 11, the void area fraction increased as the equivalent plastic strain at the center of thickness position increased. It was concluded that the void nucleation behavior of bainite-MA dual phase steels is dependent on the stress triaxiality immediately below the notch tip and the equivalent plastic strain at that position.

(5) From the finite element analysis of local plastic strain around the boundaries between bainitic ferrite and $\mathrm{MA}$, it was concluded that equivalent plastic strain becomes smaller in the case of finer MA and a longer distance between two MAs compared to coarser MA and a shorter distance between two MAs.

\section{REFERENCES}

1) N. Suzuki and M. Toyoda: Proc. 21st Int. Conf. on Offshore Mechanics and Arctic Engineering, ASME, New York, (2002), 23.

2) N. Ishikawa, S. Endo, S. Igi, A. Glover, D. Horsley, M. Ohata and M. Toyoda: Proc. Int. Pipeline Technology Conference, University of Gent, Belgium, (2004), 81.

3) S. Endo, N. Ishikawa, J. Kondo, N. Suzuki and K. Omata: Proc. Inst. Pipe Dreamer's Conf., eds by M. Toyoda and R. Denys, Yokohama, (2002), 273

4) N. Ishikawa, S. Endo and J. Kondo: JFE Tech. Rep., 7 (2006), 20.

5) T. Huper, S. Endo, N. Ishikawa and K. Osawa: ISIJ Int., 39 (1999), 288.

6) N. Ishikawa, D. M. Parks and M. Kurihara: ISIJ Int., 40 (2000), 519.

7) N. Ishikawa, D. M. Parks and M. Kurihara: ISIJ Int., 41 (2001), 76.

8) M. Okatsu, F. Kawabata and K. Amano: Proc. 16th Int. Conf. on Offshore Mechanics and Arctic Engineering, ASME, New York, (1997).

9) N. Ishikawa, H. Sueyoshi, S. Endo and N. Shikanai: Tetsu-toHagané, 91 (2005), 809.

10) M. Okatsu, T. Hoshino and K. Amano: Proc. Asia Steel Int. Conf., ISIJ, Tokyo, (2006).

11) R. Chaouadi and A. Fabry: From Charpy to Present Impact Testing, ed. by D. Francois and A. Pineau, Elsevier Science, Amsterdam, (2002), 103.

12) A. Eberle, D. Klingbeil, W. Baer, P. Wossidlo and R. Hacker: From Charpy to Present Impact Testing, eds. by D. Francois and A. Pineau, Elsevier Science, Amsterdam, (2002), 403.

13) M. Ohata, T. Fukahori and T. Mimami: Tetsu-to-Hagané, 94 (2008), 57.

14) T. Fukahori, M. Ohata, F. Minami, Y. Kayamori and T. Inoue: Tetsuto-Hagané, 94 (2008), 222.

15) H. Qiu, H. Mori, M. Enoki and T. Kishi: ISIJ Int., 39 (1999), 358.

16) M. Ohata, H. Shoji and F. Minami: Tetsu-to-Hagané, 99 (2013), 573.

17) H. Shoji, M. Ohata and F. Minami: Tetsu-to-Hagané, 100 (2014), 668.

18) A. L. Gurson: J. Eng. Mater. Tech., 99 (1977), 2.

19) V. Tvergaard and A. Needleman: Acta. Metall., 32 (1984), 157.

20) S. Tsuyama, H. Nakamichi, K. Yamada and S. Endo: ISIJ Int., 53 (2013), 317

21) T. Kobayashi, H. Matsubara and Y. Ueda: Tetsu-to-Hagané, 67 (1981), 2216.

22) H. Ikawa, H. Oshige and T. Tanoue: Trans. Jpn. Weld. Soc., 11 (1980), 87 